\title{
ESTUDO COMPARATIVO DAS CARACTERÍSTICAS FÍSICAS E FÍSICO-QUÍMICAS DE PÓS DE PITAYA ROXA (Hylocereus polyrhizus) OBTIDOS POR SECAGEM EM LEITO DE JORRO E SPRAY-DRYER
}

\author{
A. P. R. FERREIRA ${ }^{1}$, M. S. M. L. SOUSA $^{1}$, N. D. LIMA ${ }^{1}$, S. L. SOUSA ${ }^{1}$, S. M. L. SANTOS ${ }^{2}$, \\ J. M. C. $\operatorname{COSTA}^{3}$, M. R. A. AFONSO ${ }^{3}$ \\ ${ }^{1}$ Universidade Federal do Ceará, Mestranda em Ciência e Tecnologia de Alimentos \\ ${ }^{2}$ Universidade Federal do Ceará, Dra. Engenharia Química \\ ${ }^{3}$ Universidade Federal do Ceará, Departamento de Tecnologia de Alimentos \\ E-mail para contato: anaufc2009@hotmail.com
}

\begin{abstract}
RESUMO - Os processos de secagem por spray-dryer e leito de jorro têm sido amplamente utilizados para obtenção de polpas de frutas em forma de pós, no entanto, apresentam desempenho operacional diferenciado, fornecendo produtos com partículas de características qualitativas distintas. Dessa forma, esse trabalho teve por objetivo a obtenção e caracterização de polpas de pitaya em pó utilizando os processos de secagem em leito de jorro e spray-dryer. $\mathrm{O}$ experimento foi conduzido a partir da seguinte formulação: polpa de pitaya adicionada de 5\% de maltodextrina. Os resultados das análises dos pós obtidos através do leito de jorro e spray-dryer foram, respectivamente: atividade de água $(0,22 ; 0,19)$, higroscopicidade $(9,8$ e $9,4 \%)$, grau de caking (100,0; 91,3\%), pH (4,6;4,7), sólidos solúveis $\left(100,5 ; 100,6{ }^{\circ} \mathrm{Brix}\right)$. De acordo com os resultados obtidos, o processo de secagem em spray-dryer contribuiu para obtenção de polpa de pitaya em pó com melhores características em praticamente todos os parâmetros avaliados.
\end{abstract}

\section{INTRODUÇÃO}

A pitaya é uma fruta exótica, não climatérica, conhecida como fruta do dragão (Wu et al., 2006). Suas características físicas e químicas são bastante diversificadas e podem variar de acordo com a espécie (Lima et al., 2013a). Pertence à família Cactaceae e na América latina, suas principais espécies estão agrupadas em quatro gêneros: Stenocereus, Cereus, Selenicereus $e$ Hylocereus (Lima, 2013b). As principais espécies comerciais são a pitaya vermelha com polpa branca (Hylocereus undatus), pitaya vermelha com polpa vermelha (Hylocereus costaricensis), pitaya amarela com polpa branca (Selenicereus megalanthus) e, a pitaya-do-cerrado (Selenicereus setaceus) que pode ser encontrada vegetando naturalmente em regiões do Brasil. 
Devido à perecibilidade destas frutas, técnicas pós-colheitas como a desidratação vem sendo testadas. A desidratação é um processo que permite o aumento da vida útil dos produtos, redução do volume e, consequentemente, dos custos de transporte e armazenamento, além de proporcionar maior disponibilidade ao longo do ano. Dentre os métodos de secagem propostos para uso em polpas de frutas, encontram-se a secagem por fluidização (leito de jorro) e por aspersão (spray dryer). O leito de jorro é um sistema gás-sólido em que se utiliza uma corrente de gás para agitar as partículas presentes em seu interior. Segundo Duarte (2006), o movimento cíclico das partículas no interior do leito de jorro, característico deste equipamento, proporciona um bom contato fluído-partícula, garantindo elevados coeficientes de calor e de transferência de massa, o que justifica seu uso em diferentes materiais. Na secagem com o uso do spray-dryer, o alimento é pulverizado em uma câmara junto com ar quente, evaporando a água contida no produto, deixando-o sob a forma de partículas secas, recuperados posteriormente (Rosa et al., 2006).

O processo de desidratação de polpas de frutas resulta em produtos com alta pegajosidade e higroscopicidade, diminuindo o rendimento do processo. Deste modo, é fundamental a utilização de agentes carreadores, que apresentem alto peso molecular (como polímeros e gomas), antes do processo de secagem, visando facilitar a desidratação e as operações de transporte e armazenamento. Embora vários agentes encapsulantes estejam disponíveis comercialmente, a maltodextrina é o mais utilizado, principalmente em produtos com sabor e pigmento sensível (Cai e Corke 2000).

Diante do exposto e considerando a importância de agregar valor e aumentar o tempo de vida útil da pitaya, o objetivo deste trabalho foi a obtenção e caracterização de polpas de pitaya em pó utilizando processos de secagem em leito de jorro e spray-dryer.

\section{MATERIAIS E MÉTODOS}

\subsection{Obtenção da Matéria Prima}

As pitayas foram adquiridas no comércio local de Fortaleza - Ceará e posteriormente transportadas ao Laboratório de Controle de Qualidade de Alimentos e Secagem da Universidade Federal do Ceará. As frutas foram selecionadas, pesadas, lavadas e sanitizadas com solução de hipoclorito de sódio durante por 10 minutos.

Em seguida os frutos foram submetidos ao processo de extração para retirada da polpa (juntamente com sementes) e posterior trituração em liquidificador. Em seguida a polpa passou por peneiramento para remoção das sementes. A polpa extraída foi acondicionada em recipientes de polietileno e mantidas sob congelamento a $-18{ }^{\circ} \mathrm{C}$ até o momento de sua utilização nos experimentos. 


\subsection{Secagem em Spray-dryer e Leito de Jorro}

O procedimento utilizado para secagem da polpa de pitaya está representado na Figura 1. Após o descongelamento, foi elaborada uma formulação composta de polpa de pitaya e 5\% de maltodextrina (DE 20), em seguida a solução resultante foi então homogeneizada e dividida em duas porções iguais.

Uma parte da solução de polpa foi submetida à secagem em leito de jorro (modelo FBD 3.0, LABMAQ, Brasil), nas seguintes condições: temperatura de $90{ }^{\circ} \mathrm{C}$, vazão do ar de fluidização (soprador) de ar no bico atomizador e no soprador foram de $1,7 \mathrm{~m}^{3} \cdot \mathrm{min}^{-1} \mathrm{e}$ vazão de alimentação de $4,9 \mathrm{~mL} \cdot \mathrm{min}^{-1}$. Foram utilizados $400 \mathrm{~g}$ de inertes de polietileno de alta densidade para otimizar o processo de secagem.

A segunda porção da formulação foi submetida à secagem em um spray-dryer (modelo MSD 1.0 da marca LABMAQ, Brasil), utilizando um bico pneumático de 1,2 $\mathrm{mm}$ e, as seguintes variáveis de processo: vazão de alimentação da mistura $\left(0,5 \mathrm{~L} \cdot \mathrm{h}^{-1}\right)$, vazão de ar quente $\left(3,5 \mathrm{~L} \cdot \mathrm{h}^{-1}\right)$, temperatura de entrada $\left(150^{\circ} \mathrm{C}\right)$ sendo mantidas constantes a velocidade do ar $\left(30 \mathrm{~L}^{\circ} \mathrm{min}^{-1}\right)$. Após o processo, as amostras foram armazenadas em recipientes herméticos (e protegidos da luminosidade) no interior de dessecadores, até o momento da realização das análises.

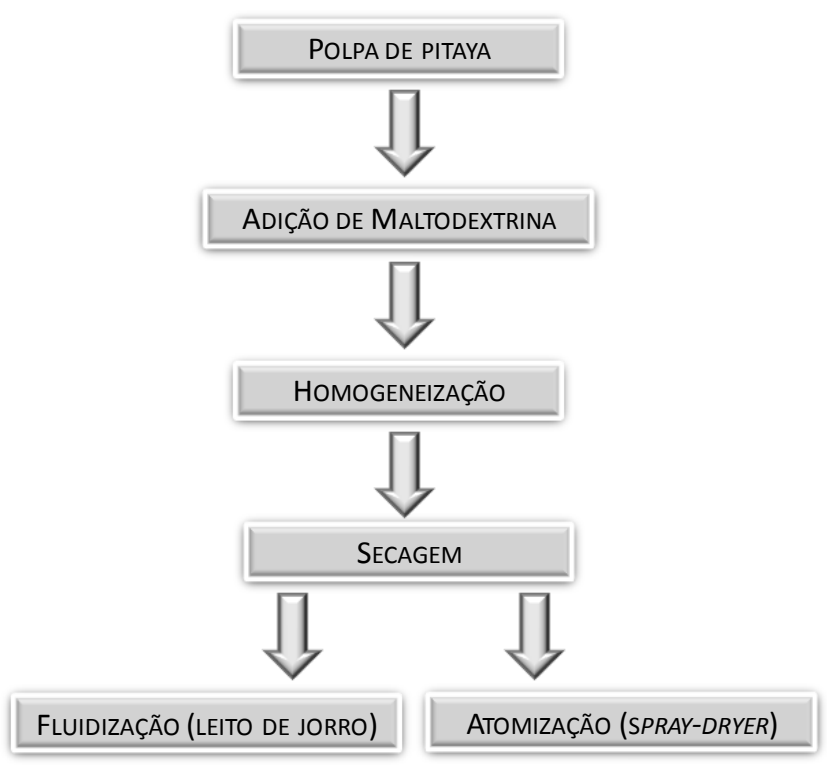

Figura 1 - Fluxograma do processo de obtenção de polpa de pitaya roxa em pó. 


\section{9 a 22 de outubro de 2014 \\ Florianópolis/SC}

\subsection{Caracterização física e físico-química das polpas de pitaya roxa em pó obtidas a partir de secagem em leito de jorro e spray dryer}

Após a obtenção do produto em pó (polpa de pitaya) a caracterização foi realizada a partir das seguintes análises: $\mathrm{pH}$, sólidos solúveis, atividade de água, higroscopicidade, grau de Caking, além da medida instrumental de cor.

$\mathrm{O} \mathrm{pH}$ foi determinado através de leitura em pHmetro, previamente calibrado em soluções tampões de $\mathrm{pH}$ 4,0 e 7,0. Os sólidos solúveis foram determinados em refratômetro, sendo o resultado expresso em ${ }^{\circ}$ Brix a $20^{\circ} \mathrm{C}$ (AOAC, 1992). A atividade de água dos pós foi determinada com o auxílio de um medidor de atividade de água (modelo AQUALab 4TEV) a $25{ }^{\circ} \mathrm{C}$. A análise de higroscopicidade foi determinada por diferença de massa segundo a metodologia descrita por Goula e Adamaphoulos (2008). Já o grau de caking foi obtido por análise granulométrica utilizando um agitador de peneiras (Bertel LTDA) seguindo a metodologia descrita por Jaya e Das (2004).

\section{RESULTADOS E DISCUSSÃO}

\subsection{Caracterização física e físico-química das polpas de pitaya roxa em pó obtidas a partir de secagem em leito de jorro e spray dryer}

Os resultados referentes à caracterização dos pós de pitaya obtidos nesse estudo estão representados na Tabela 1 .

Tabela 1- Resultados das análises físicas e físico-químicas realizadas nos pós de pitaya roxa.

\begin{tabular}{|c|c|c|c|c|c|}
\hline Amostra & Atividade de água & $\mathrm{pH}$ & $\begin{array}{c}\text { Sólidos solúveis } \\
\left({ }^{\circ} \text { Brix }\right)\end{array}$ & $\begin{array}{c}\text { Higroscopicidade } \\
(\%)\end{array}$ & $\begin{array}{c}\text { Grau de caking } \\
(\%)\end{array}$ \\
\hline Polpa integral & 0,98 & 4,5 & 6,8 & - & - \\
\hline Polpa (5\% de maltodextrina) & 0,98 & - & 11,1 & - & - \\
\hline Pó obtido no Leito de jorro* & 0,22 & 4,6 & 100,5 & 9,8 & 100,0 \\
\hline Pó obtido no Spray dryer* & 0,19 & 4,7 & 100,6 & 9,4 & 91,3 \\
\hline
\end{tabular}

Fonte: próprio autor. * Pó com $5 \%$ de maltodextrina.

Em relação à atividade de água, a polpa integral de pitaya roxa e a formulação com maltodextrina apresentaram mesmo valor médio de 0,98 . Em relação ao pó de pitaya roxa obtido em leito de jorro, o valor médio da atividade de água encontrado foi de 0,22, indicando que houve redução de 77,6\% no teor de água após o processo de secagem quando compara-se ao valor da polpa integral. O pó de pitaya roxa obtido no spray-dryer apresentou valor médio de 0,19 , ocorrendo redução de $80,6 \%$ na atividade de água do produto. A redução na atividade de água é importante pelo fato de que contribui ao produto em pó (polpa de pitaya) uma maior estabilidade microbiológica e, consequentemente, um aumento em seu tempo de vida útil.

A polpa de pitaya apresentou um $\mathrm{pH}$ médio de 4,5, bem próximo aos valores encontrados por Santos et al (2012) e por Souza et al (2006). Para a pitaya em pó obtido no leito de jorro e no spray-dryer, foi observado que os valores não diferiram significativamente entre si, encontrando 


\section{9 a 22 de outubro de 2014 \\ Florianópolis/SC}

se um valor de 4,6 para o pó obtido em leito de jorro e 4,7 para o pó obtido no spray-dryer. O teor de sólidos solúveis na polpa de pitaya roxa foi de $6,8{ }^{\circ} \mathrm{Brix}$, inferior aos valores encontrados por Souza et al (2006) que foi de $7,01^{\circ}$ Brix. Para a pitaya roxa em pó obtido no leito de jorro e no spray-dryer, foi observado que os valores de sólidos solúveis não diferiram significativamente entre si, encontrando se um valor de 100,5 para o pó obtido em leito de jorro e 100,6 para o pó obtido no spray-dryer, porém, diferiram significativamente em relação à polpa de pitaya e a mistura de polpa de pitaya com maltodextrina.

A higroscopicidade dos pós esta relacionada a capacidade de absorver a umidade do ambiente. De acordo com a Tabela 2, que dispõe da classificação de Gea Niro Research Laboratory (2003), o pó da polpa de pitaya roxa obtida tanto no leito de jorro como no spraydryer são considerados não higroscópicos.

Tabela 2 - Padrões de higroscopicidade dos pós

\begin{tabular}{lc}
\hline \multicolumn{1}{c}{ Higroscopicidade } & Valor de referência (\%) \\
\hline Não higroscópico & $<10$ \\
Ligeiramente higroscópico & $10,1-15,0$ \\
Higroscópico & $15,1-20,0$ \\
Muito higroscópico & $20,1-25,0$ \\
Extremamente higroscópico & $>25,0$ \\
\hline
\end{tabular}

Fonte: GEA Niro Research Laboratory, 2003

O caking consiste em um fenômeno deletério no qual os pós alimentícios por modificação do ambiente, entre estes a variação de umidade, transformam-se em um material endurecido e aglomerado com consequente perda de funcionalidade e qualidade, além das perdas econômicas envolvidas (Barbosa-Cánovas et al,2005). De acordo com a Tabela 3, a pitaya roxa em pó obtida em leito de jorro apresentou $100 \%$ de aglomeração, caracterizando-se como um pó com extrema formação de caking. A pitaya roxa em pó obtida no spray-dryer apresentou porcentagem de aglomeração de 91,3\%, caracterizando-se como um pó com muita formação caking. Esse resultado é justificado pela quantidade significativa de açúcares em sua composição, o que favorece o processo de aglomeração.

Tabela 3 - Padrões de grau de caking dos pós

\begin{tabular}{lc}
\hline \multicolumn{1}{c}{ Grau de caking } & Valor de referência (\%) \\
\hline Não há formação de caking & $<10,0$ \\
Ligeira formação de caking & $10,1-20,0$ \\
Pó com formação de caking & $20,1-50,0$ \\
Pó com muita formação de caking & $>50,0$ \\
Pó com extrema formação de caking & 100,0 \\
\hline
\end{tabular}

Fonte: GEA Niro Research Laboratory 2003 


\section{CONCLUSÃO}

Os pós obtidos pelas secagens em spray-dryer e leito de jorro embora não tenham se apresentado higroscópicos, possuem muita e extrema formação de caking, respectivamente. Esses pós podem se aglomerar em condições normais de armazenamento, sendo necessárias novas investigações com o objetivo de melhorar essa característica. O processo de secagem em spraydryer contribuiu para obtenção de polpa de pitaya em pó com melhores características higroscópicas e menor atividade de água.

\section{REFERÊNCIAS}

A.O.A.C. - ASSOCIATION OF OFICIAL ANALYTICAL CHEMISTS. Official Methods of Analysis of the Association of Official Analytical Chemists. Arlington, 1992.

BARBOSA-CÁNOVAS, G. V. et al. Undesirable Phenomena and Their Relation to Processing. Food Powders: physical properties, processing and functionality. New York: Kluwer Academic/Plenum Publishers. 2005. p. 305-359.

CAI, Y. Z.; CORKE, H. Production and properties of spray-dried Amaranthus Betacyanin Pigments. Journal of Food Science, v. 65, n. 6, p. 1248-1252, 2000.

DUARTE, C. R. Estudo experimental e de simulação da fluidodinâmica e recobrimento em leito de jorro, Tese de Doutorado, PPGEQ/UFU - Uberlândia/MG, 194p, 2006.

GEA Niro Research Laboratory. GEA Niro analytical methods. 2006.

GOULA, A. M.; ADAMOPOULOS, K. G. Water sorption isotherms and glass transition temperature of spray dried tomato pulp. Journal of Food Engineering, v. 85, p. 73-83, 2008.

JAYA, S.; DAS, H. Effect of maltodextrin, glycerol monostearate and tricalcium phosphate on vacuum dried mango powders properties. Journal of Food Engineering, v.63, p. 125-134, 2004.

LIMA, C. A. et al. Diversidade genética intra e interespecífica de pitaya com base nas características físico-químicas de frutos. Rev. Bras. Frutic., Jaboticabal - SP, v. 35, n. 4, p. 1066-1072, 2013a.

LIMA, C. A. et al. Características físico-químicas, polifenóis e flavonóides amarelos em frutos de espécies de pitayas comerciais e nativas do Cerrado. Rev. Bras. Frutic., v.35, n.2, p. 
565-570. 2013b.

ROSA, E. D. et al. Secagem por atomização na indústria alimentícia: fundamentos e aplicações. In: Jornada Científica da Fazu/Faculdades Associadas de Uberaba, 5, 2006, Uberaba, Anais... Uberaba: FAZU, 2006.

SANTOS, R. K. A. I. et al. Caracterização física e química da pitaya vermelha (Hylocereus undatus). In: FORÚM DE ENSINO, PESQUISA E EXTENSÃO, 6., 2012, Montes Claros. Anais. Montes Claros: FEPEG, 2012.

SOUZA, L. S. et al. Características físico-químicas de frutos de pitaya CPAC-PY-01 cultivada no cerrado. Planaltina, DF: Embrapa Cerrados, 2006.

WU, L.C. et al. A. Antioxidant and antiproliferative activities of red pitaya. Food Chemistry v. 95, p. 319-327, 2006. 